\title{
Os desafios da globalização e a imaginação cosmopolita: as implicações do Antropoceno*
}

Recebido: 18.04 .18

Aprovado: 14.06 .18

\section{Gerard Delanty**}

Resumo: 0 trabalho destaca que o conceito de Antropoceno refere-se a uma dimensão temporal no tempo geológico: é a época em que os seres humanos provocaram uma grande transformação na estrutura física da Terra. Trata-se de uma forma de autocompreensão histórica. Representa, assim, uma grande transformação na natureza geofísica do sistema Terra que coincide com a transformação mundial provocada pelo capitalismo e pela ocidentalização. O Antropoceno está inextricavelmente relacionado a questões sociológicas que dizem respeito ao capitalismo, à guerra, ao poder e à desigualdade em escala global. O texto destaca que a noção de Antropoceno não é simplesmente uma condição objetiva da mudança planetária, ou outro termo para a mudança climática, mas é, acima de tudo, uma categoria interpretativa pela qual as sociedades contemporâneas refletem sobre si mesmas e sobre a própria vida e reinventam seu espaço e tempo.

Palavras chaves: Modernidade global. Mudança epocal. Evolução humana e biológica. História da Terra. Antropoceno.

\section{Challenges of globalization and the cosmopolitan imagination: the implications of the Anthropocene}

Abstract: The work emphasizes that the concept of Anthropocene refers to a temporal dimension within geological time: the era when human beings brought about a great transformation in the Earth's physical structure. It is a form of historical self-understanding that represents a great transformation in the Earth system's geophysical nature, coeval with the worldwide transformation caused by capitalism and westernization. The Anthropocene is inextricably bound up with sociological questions concerning capitalism, war, power, and inequality on a global scale. The text draws attention to the fact that the notion of Anthropocene does not simply refer to climate change, but is above all an interpretative category, by means of which contemporary societies may reflect on themselves and on life itself, and reinvent their space and time.

Keywords: Global modernity. Epochal change. Human and biological evolution. History of the Earth. Anthropocene.

\author{
* Palestra de \\ abertura, Congresso \\ da Associação \\ Brasileira de \\ Sociologia, 26 a 29 \\ de julho de 2017, \\ Brasília. \\ Tradução: Leo Lopes. \\ ** Gerard Delanty \\ é professor de \\ sociologia e \\ pensamento social e \\ político, Universidade \\ de Sussex, Brighton, \\ Reino Unido. Suas \\ publicações mais \\ recentes incluem \\ The European \\ heritage: a critical \\ re-interpretation. \\ London: Routledge, \\ 2017; Formations of \\ European modernity: \\ a historical and \\ political sociology \\ of Europe. Suffolk \\ (UK): Palgrave 2013; \\ e The cosmopolitan \\ imagination: the \\ renewal of critical \\ social theory. \\ Cambridge (UK): \\ Cambridge University \\ Press, 2009. \\ $<$ g.delanty@sussex. \\ ac.uk>.
}




\section{Introdução}

N os anos 1990, a ideia de globalização tornou-se um dos conceitos mais importantes nas ciências sociais. Isso levou a um repensar da natureza da sociologia e a pesquisas muito importantes. Neste artigo, argumento que o desafio da globalização foi minimizado. Há duas razões para isso. A primeira é que um olhar retroativo sobre a teoria sociológica clássica revela que, em verdade, ela estava muito consciente da chegada de um mundo globalmente conectado, que acompanhou a modernidade. A globalização, embora o termo não tenha sido usado, já era uma força no mundo, se não desde o início da civilização humana, certamente desde o intercâmbio colombiano do século XVI. A tremenda transformação trazida pela comunicação eletrônica, desde o final da década de 1980, deve ser posicionada em uma perspectiva histórica mais ampla sobre as principais transformações históricas que precedem a modernidade. Em segundo lugar - justamente o meu principal interesse neste artigo -, os recentes desenvolvimentos em torno da noção de Antropoceno requerem uma compreensão mais profunda da natureza espacial e temporal da sociedade humana daquela que pode ser capturada pela noção de globalização. A ciência social e a sociologia em particular não digeriram completamente a chegada do Antropoceno, o qual, afirmo, requer um repensar importante da imaginação sociológica, uma vez que oferece um relato da transformação epocal e é o próprio nome da era atual. No entanto, não estou sugerindo que a teoria sociológica esteja agora redundante. Os problemas da sociologia moderna e os desafios atuais não estão tão distantes um do outro, já que, comum a ambos, é a explicação da mudança epocal.

Se existe alguma continuidade no empreendimento sociológico esta é a preocupação em compreender as grandes transformações históricas. Os desafios atuais são diferentes daqueles do final do século XIX, quando a sociologia emergiu. Mas, comum às duas épocas é o desafio de dar sentido ao tempo presente à luz da experiência histórica modificada. A quintessência da imaginação sociológica foi descrita em 1959 por Charles Wright Mills - que nasceu há cem anos - em uma formulação clássica que ainda é convincente:

\footnotetext{
A imaginação sociológica capacita seu possuidor a entender a cena histórica mais ampla em termos do significado para a vida interior e o curso externo de uma variedade de indivíduos. [...] É a capacidade de abarcar desde as transformações impessoais e remotas às características mais íntimas do eu humano - e ver as relações entre os dois (Mills, 1970: 11 e 14).
}

Mills enfatizou o desafio de compreender a realidade histórica mais ampla da história mundial, na medida em que esta se manifesta na vida dos povos. De suas di- 
ferentes maneiras, os grandes sociólogos clássicos tentaram fazer isso, pois tinham um entendimento muito histórico da tarefa sociológica.

Uma das marcas da sociologia moderna é a preocupação em imprimir um sentido às grandes transformações históricas. A sociologia clássica era profundamente histórica, mas sua abordagem sempre se distinguiu da abordagem do historiador, na medida em que buscava entender a especificidade do tempo presente em termos da totalidade das relações sociais e enxergar o passado com um olhar para o futuro. Suas questões eram diferentes das dos historiadores, bem como seus métodos, que eram geralmente comparativos e interpretativos. Existe um risco de que esta característica tenha se perdido e que uma nova geração de historiadores globais esteja tomando a iniciativa de dar sentido à mudança epocal. Portanto, este artigo é um apelo para a recuperação da sociologia histórica macrocomparativa e um foco nas grandes transformações históricas.

Minha afirmação é que a preocupação com transformações epocais é uma característica distintiva da sociologia. Esta não é apenas uma preocupação acadêmica, é provavelmente uma das correntes que definem o mundo de hoje. A turbulência do mundo contemporâneo se deve, em parte, a diferentes interpretações das principais mudanças sociais e políticas. A esse respeito, a sociologia tem uma tarefa específica, a saber, oferecer aos públicos maneiras pelas quais as pessoas possam ver suas vidas através do prisma do mundo social mais amplo e da história mundial.

\section{Principais transformações históricas}

\section{e a entrada do Antropoceno}

O mundo moderno foi moldado por uma série de rupturas históricas que levaram à reconfiguração do tempo e do espaço. Por trás dessas rupturas estavam dinâmicas e processos que continuam a moldar nosso mundo e que criam um grau de continuidade. Vamos avaliar essas rupturas e continuidades, que podem ser caracterizadas de várias maneiras. Esta é minha reconstrução.

Sem dúvida, o primeiro hiato foi a descoberta da América pelos europeus. Depois de 1492, nem o Novo nem o Velho Mundo eram os mesmos. A Era dos Descobrimentos e a percepção do mundo como um globo, juntamente com o domínio da Terra que veio concomitante à Revolução Científica, foi o primeiro grande momento transformador na história das sociedades humanas. Isso levou à expansão mundial das potências coloniais europeias, à ascensão do capitalismo e ao domínio da ciência. 
A grande transformação na sequência veio depois de 1789, quando as ideias da Revolução Francesa transformaram o imaginário político na Europa e em todo o continente americano. No século XIX, o capitalismo tornou-se cada vez mais enraizado no mundo como um todo. Pode ter sido contido por contramovimentos, como Karl Polanyi argumentou, mas nada deteve sua ascensão implacável.

A perspectiva de uma contramodernidade não se manifestou até 1917 e a subsequente ascensão da URSS, quando, pela primeira vez, uma ordem inteiramente diferente de modernidade foi criada. O período que se seguiu ao final da Primeira Guerra Mundial pode ser visto como um grande momento de transformação histórica que presenciou o surgimento de diferentes potências totalitárias, das quais a soviética foi a mais durável.

A transformação histórica seguinte veio com o desaparecimento dessa ordem em 1989-1990 e a extensão do capitalismo para o mundo inteiro, que neste momento também inclui a China. Um momento acompanhado pelo surgimento da tecnologia da informação. Não pode haver dúvida de que a queda do Muro de Berlim e os eventos que se seguiram representaram uma grande transformação no mundo moderno. Isso prometia uma visão de um mundo mais aberto, no qual o indivíduo poderia desfrutar de novas liberdades. A ilusão foi abalada depois de 2003, com a Guerra do Iraque e uma nova era de tecnossegurança.

Agora, o tempo presente, o centenário da Revolução de Outubro podem ser vistos também como um momento de transformação histórica, embora de um tipo muito incerto. É a primeira vez em que o capitalismo parece estar entrando em uma fase crítica, após as convulsões de 2008-2009 e a crise do neoliberalismo refletida em economias de crescimento baixo ou nulo, o colapso das ditaduras árabes e a crise da União Europeia. É um período de profunda incerteza e de questionamento de muitas suposições sobre o significado da verdade e da democracia em uma era de novas políticas populistas autoritárias. É um período de grande decepção com as promessas da modernidade e da democracia.

Uma característica de todas as transformações históricas anteriores foi, para o bem ou para o mal, o impacto de formas fundamentalmente novas de ver o mundo. Novas ideias surgiram e revelaram novas visões do mundo humano e natural. Isto é o que está ausente hoje. Tanto no Brasil, no Reino Unido como na Europa ou nos Estados Unidos, há um profundo pessimismo, se não desespero, que um mundo melhor não seja possível. No entanto, quero sugerir que uma visão sociológica da situação atual demandaria olhar para além do imediatismo do presente e identificar características mais formativas da sociedade contemporânea. É neste contexto que 
a noção do Antropoceno é um quadro de referência relevante para a sociologia, uma vez que se defronta com os desafios da atualidade.

A designação do tempo atual como modernidade, modernidade global ou o pós-modernidade ou ainda, como está atualmente na moda, o pós-humano, poderia ser mais precisamente chamada de Antropoceno. Esta noção pode ser considerada sociologicamente significativa? Ou ela aponta para a obsolescência da própria noção de social, como argumentado pelo pensamento pós-humanista? Vou me esforçar em demonstrar - contrariamente à posição pós-humanista - que ela pode ser uma maneira útil de compreender a transformação do mundo moderno e que é uma maneira pela qual as sociedades contemporâneas podem conhecer e governar a si mesmas. Nesse sentido, é uma forma de autocompreensão histórica. Também pode ser uma maneira de corrigir alguns dos pontos cegos da teoria social moderna, por exemplo, seu suposto eurocentrismo, a visão do hemisfério norte sobre mundo e o impacto da história natural da Terra sobre o mundo humano. No entanto, como também argumentarei, a noção de Antropoceno deve ser observada de uma perspectiva mais sociológica; importa desmistificar algumas das características associadas à ideia.

\section{Novos desafios:}

\section{o Antropoceno, o tempo e a modernidade}

O Antropoceno é, antes de tudo, um conceito temporal no tempo geológico: a Idade Humana. É a época em que os seres humanos provocaram uma grande transformação na estrutura física da Terra. Até agora - desde agosto de 2016 -, isto tem sido aceito pelo Grupo de Trabalho em Antropoceno da Comissão Internacional sobre Estratigrafia ${ }^{1}$. Refere-se a uma época em que o mundo humano e a Terra física entram em uma nova fase. É claro que é também um conceito político, na medida em que implica uma posição crítica sobre as consequências do que chamo "relação mundo-Terra" e, como argumentarei adiante, é também um conceito cultural na medida em que implica uma interpretação dos tempos atuais. Essas três dimensões - a temporal, a política e a cultural - a tornam potencialmente relevante para a ciência social e relacionada diretamente com as preocupações centrais da teoria sociológica clássica, à medida que ela enfrenta novos desafios decorrentes de novas percepções surgidas das ciências naturais. Os desenvolvimentos nos campos da geologia e da biologia estão forçando as ciências sociais para além do legado científico do século XIX.

A ideia do Antropoceno sugere uma nova abordagem da temporalidade. Eu argumento que existem três temporalidades que até agora foram vistas como separadas, mas que precisam ser vistas como interconectadas. A primeira é o Tempo da 
2. Homo sapiens sapiens é distinto de seus ancestrais, Homo sapiens, e de outras espécies, como o Homo idaltu.
Terra (o tempo da história da Terra); a segunda, o Tempo Humano (a história do Homo sapiens sapiens, ou seja, os humanos modernos, distintos do Homo sapiens ${ }^{2}$ anterior); e a terceiro é o Tempo Histórico (o tempo profundo das sociedades humanas antes do surgimento das civilizações). Reconstruir seu emaranhado exigiria algo como uma história integrada das ciências humanas, sociais e naturais. Pode haver um papel nisso para a sociologia e para a teoria social. Certamente há implicações para a filosofia das ciências sociais, uma vez que um número de pressuposições ontológicas e epistemológicas do pensamento social clássico precisariam ser revisadas em uma época em que a realidade natural carrega, cada vez mais, a assinatura dos humanos. Voltarei a discutir o tema na conclusão. No entanto, a teoria sociológica pode oferecer novos olhares sobre a análise do tempo presente em termos de tais intersecções que estão moldando transformações em sociedades humanas que não são totalmente compreendidas pelo conjunto de teorias e conceitos existente (modernidade e globalização, por exemplo).

Como um termo que designa a presente época em Escalas de Tempo Geológico enquanto ruptura com a Época Holocênica anterior, que começou há 12 mil anos, ao final da última Idade do Gelo, o Antropoceno expõe o impacto do Tempo Histórico sobre o Tempo da Terra. Ele traz, assim, uma nova perspectiva para o problema da periodização. Embora grande parte da discussão sobre a periodização das Escalas de Tempo Geológico tenha sido conduzida dentro da disciplina de geologia e no contexto mais amplo da ciência do sistema da Terra, ela teve ramificações para as ciências humanas e sociais. Das várias teorias sobre do surgimento do Antropoceno e, portanto, uma nova Época geológica dentro do Período Quaternário, a que conquistou mais ou menos consenso dentro da ciência do sistema Terra é a chamada Grande Aceleração, que localiza o ponto de origem no período pós-1945. Essa periodização substituiu os relatos alternativos, que incluem o "Antropoceno Antigo", que postula o início do Antropoceno com o início da civilização no Pleistoceno Superior ou o início da Revolução Industrial. A Grande Aceleração começou entre 1950 e 1964, mas pode ser formalmente datada em 16 de julho de 1945, com a detonação da primeira bomba atômica. Há claras evidências de um pico de radiocarbono atmosférico registrado em 1964, em anéis de árvores, e que pode ser atribuído a testes nucleares, que vão além da variabilidade natural (Zalasiewicz et alii, 2011). Qualquer que seja a origem específica, agora é amplamente aceito estar nesse período - essencialmente nos últimos 50 anos -, quando a mudança planetária também se torna evidente no sistema Terra como um todo. Isso inclui a mudança climática, mas também uma série de outras mudanças, como as relacionadas aos oceanos, por exemplo, a formação do plástico como uma nova rocha. Evidências recentes sugerem que o plástico, uma invenção humana de 1907, se combinou com o sedimento natural para formar um novo estrato de rocha. 
O Antropoceno representa, assim, uma grande transformação na natureza geofísica do sistema Terra, que coincide, mais ou menos, com a transformação mundial provocada pelo capitalismo e pela ocidentalização. A Segunda Guerra Mundial foi em si um fator contribuinte importante - tal como a Guerra Fria -, na medida em que a permanente conduta de guerra na segunda metade do século passado levou a um aumento maciço de energia em uma escala desconhecida anteriormente (Steffen et alii, 2011; McNeil \& Engelke, 2014). É aqui que a ciência da terra se encontra com as ciências sociais.

Uma reconstrução sociológica histórica do Antropoceno faria distinção entre os antecedentes - neste caso, a consolidação do capitalismo industrial no século XIX - e seu amadurecimento na segunda metade do século XX, com o advento de novas tecnologias e o impacto mundial da industrialização, que incluem países neoextrativistas, incluindo Brasil, China, Índia, África do Sul e Indonésia.

A ciência do sistema Terra dá conta da maior parte da temporalidade, da extensão e importância da evidência geofísica da transformação do sistema Terra. No entanto, é interessante ver que enquanto um certo consenso parece emergir no contexto da ciência do sistema Terra, ainda há controvérsias e questionamentos sobre a aplicação das Escalas de Tempo Geológico que formam a base da geologia no que diz respeito ao problema da periodização. Mas a periodização se estende ao futuro: o Antropoceno é distópico, ou admite a possibilidade de redenção como projeto político positivo? Nestes termos, a temporalidade do Antropoceno coincide em parte com a modernidade, também ela mesma uma categoria temporal (a idade do novo, a afirmação do tempo presente e da liberdade humana). Os primeiros sinais do Antropoceno coincidem com o surgimento da modernidade na Europa, mas este se consolida como uma Época Geológica à medida que variedades de modernidade tomam forma em todo o mundo. No entanto, ele parece englobar um espectro mais amplo do que o da modernidade e, a rigor, refere-se apenas aos últimos 50 anos. Embora eu não esteja argumentando que isso torne a noção de modernidade redundante, certamente Ihe atribui uma importância reduzida.

O Antropoceno está inextricavelmente relacionado a questões sociológicas que dizem respeito ao capitalismo, à guerra, ao poder e à desigualdade em escala global. No entanto, a ciência social permaneceu relativamente silenciosa quanto às principais forças que provocaram essas mudanças históricas na Terra e em como elas deveriam ser interpretadas. Como categoria temporal, o Antropoceno não é apenas uma época natural, mas uma era do tempo humano e histórico.

Antes de considerar essas dimensões do tempo, gostaria de ressaltar que, tomando tudo em conta, o Antropoceno - assim como a ideia de modernidade - é mais 
que uma categoria temporal e também mais que espacial. É ainda uma categoria cultural, um prisma, na verdade até mesmo um vórtice através do qual as sociedades contemporâneas podem ser interpretadas. Dada a predileção dos geólogos por destacar datas específicas, eu sugeriria que 1986 marca um momento no tempo em que a experiência histórica mudou, como resultado de uma nova consciência de que o mundo humano e a Terra formam uma unidade sob ameaça. Foi quando dois eventos relacionados coincidiram: a explosão de Chernobyl, em 26 de abril de 1986, e a descoberta do buraco na camada de ozônio sobre a Antártida, em 1985-1986.

\section{O Antropoceno e o tempo humano}

Grande parte do debate sobre o Antropoceno diz respeito ao problema das origens: quando começou, que evidência pode ser dada, em que ponto e onde um limite pode ser estabelecido nas Escalas de Tempo Geológico? Como argumentei, quanto mais se enfrenta esse problema, mais ele se emaranha em questões que trazem o problema da periodização geológica para o contexto histórico e sociológico da modernidade. Aqui, inevitavelmente, nos envolvemos com questões de consciência e de interpretação da mudança epocal.

Existem outras implicações. O Antropoceno levanta questões importantes sobre a natureza do tempo humano. Primeiro, a própria concepção do sistema da Terra inclui a vida em si - e isso inclui a vida humana -, já que a Terra é composta não apenas da formação rochosa, mas abrange os oceanos, a atmosfera, o campo magnético e a própria vida. Reconhece-se agora que, sem a vida, a terra não seria muito diferente do inabitável Vênus. A chegada do tipo particular de vida representada pelo Homo sapiens sapiens, o assunto da investigação científica humana e social, é relativamente tardia, tomando forma de 60 a 30 mil anos atrás, quando a mente humana emergiu com a evolução do lóbulo frontal avançado, um desenvolvimento que ocorreu juntamente com o início de uma grande mudança cultural na

3. O Homo sapiens arcaico erradicou pelo menos duas outras espécies hominídeas, Homo habilis e Homo erectus. Os neandertais, que viviam principalmente na Europa até pouco mais de 30.000 anos atrás, também foram quase certamente, exterminados pelo Homo sapiens. vida do Homo sapiens, que desenvolveu capacidades cognitivas e estéticas para a representação cultural (na arte), a consciência (religião, o enterro dos mortos) e a tecnologia, desenvolvimentos que levaram ao início do tempo histórico (Mithen, 1998). Foi também uma época em que esta espécie erradicou os hominídeos rivais e provou sua a superioridade sobre todos os demais hominídeos - o gênero mais amplo3.

Uma questão que agora pode ser colocada é se os seres humanos chegaram a um ponto em que seja possível falar de uma transformação evolucionária que coincida com o Antropoceno. Aqui, os desenvolvimentos em biologia são significativos. As populações humanas e não humanas evoluíram juntas e se modificaram contínua 
e mutuamente (Russell, 2011). O corpo humano, devido a processos de aceleração química, é, muito provavelmente, fisiologicamente diferente do corpo humano anterior a 1945 (Thomas, 2014). Já foi afirmado que sete por cento dos genes humanos sofreram mudanças recentes. A vida pode agora ser sintetizada pelos seres humanos que, por sua vez, também são transformados por sua capacidade de mudança.

Os desenvolvimentos neurológicos, biotecnológicos e fisiológicos em relação à vida humana criaram o "corpo tóxico", mas também produziram um ser humano que é muito diferente daquele que viveu há alguns séculos, em termos de saúde, longevidade, capacidade cognitiva. Durante grande parte da história, a vida humana foi dominada pela experiência do sofrimento. Para Max Weber, esse foi um dos fatores-chave que explicaram a ascensão das religiões mundiais. Como Bryan Turner (2017) argumentou, a ciência e a tecnologia hoje têm a capacidade de reduzir consideravelmente o sofrimento humano, colocando em xeque a base ontológica da religião.

Esses acontecimentos podem ser sinais precoces de uma nova fase evolucionária na vida do Homo sapiens sapiens e, portanto, de uma grande mudança na condição humana que pode ser comparada à transformação ocorrida de 60 a 30 mil anos atrás, quando os desenvolvimentos no lóbulo frontal do cérebro ocorreram e levaram à transformação cultural. Tais questões são, obviamente, sociologicamente pertinentes, mas devem ser vistas no contexto mais amplo de uma grande transformação epocal que pode ser provavelmente melhor localizada no âmbito do Antropoceno. A evolução dos humanos modernos - Homo sapiens sapiens - se não para uma nova espécie, pelo menos para um subtipo da forma atual, se justapõe ao Antropoceno, que, e isso não deve ser esquecido, também é uma projeção - do presente - de uma época que acaba de começar. No entanto, é preciso cautela, uma vez que as evidências da psicologia evolutiva e da biologia evolutiva são inconclusivas sobre ter ocorrido uma modificação genética nos seres humanos modernos nos últimos tempos, que dirá se ela ocorreu por adaptação (Pinker 2011: 742-751). Na verdade, pode ser que falemos apenas de evolução bioquímica. A evolução é agora, de qualquer forma, reconhecida por assumir uma diversidade de formas e não implica necessariamente a formação de novas espécies (Russell, 2011).

A ideia do Antropoceno levanta a questão normativa sobre se os humanos são agora capazes de conceber os meios políticos e tecnológicos necessários para resolver os problemas do Antropoceno. Aqui reside o perigo do antropocentrismo: uma ênfase excessiva nos seres humanos como os senhores do mundo. Por um lado, a noção do Antropoceno, como a Idade dos Humanos, dá aos humanos um lugar especial na 
4. Ver <http:// www.pewforum. org/2015/04/02/ religious-projections-20102050/>.

5. Ver <https://www. theguardian.com/ commentisfree/ 2017/apr/26/ discovery-of-alienlife-religion-willsurvive>. história da Terra, mesmo que sejam os agentes de sua destruição. Por outro lado, existe o perigo de que os seres humanos sejam superestimados por serem agentes de ambos, destruição e redenção. Isso negligencia o fato de que, não importando o que os humanos façam, eles não serão capazes de mudar a Terra a não ser por torná-la inabitável, pois a Terra sobreviverá a seus residentes temporários.

A possibilidade - mesmo que teórica - de outras formas de vida serem descobertas não pode ser desconsiderada. De fato, já se especula que essa possibilidade levante questões importantes para a religião, em particular para aquelas que dão um lugar especial ao Homo sapiens sapiens como o centro de um universo criado. Em vista da ascensão mundial da religião, isso não é uma fantasia ${ }^{4}$. O Antropoceno é também a era do crescimento da religião em todo o mundo. A Nasa, em 2014, doou mais de um milhão de dólares ao centro de Investigação Teológica dos Estados Unidos para o estudo das implicações sociais do que hoje é chamado de astrobiologia ${ }^{5}$. Isso ilustra o fato sociológico de que a ideia de Antropoceno não é simplesmente uma designação geológica, mas um domínio da autocompreensão histórica.

A ideia do Antropoceno deu um novo destaque à reflexão sobre a condição humana, o que significa ser humano e humanidade como espécie. Em grande parte da recepção popular existe um risco latente de uma despolitização do Antropoceno, não apenas como uma época irreversível, mas desprovida de poder e desigualdade. A ideia de um Antropoceno também pode causar uma simplificação excessiva de processos complexos (ver Luke, 2017). Um corretivo sociológico é importante aqui para chamar a atenção sobre a noção de humanidade como um todo, uma ideia muito abstrata já que a sua pegada negativa deriva em grande parte do mundo desenvolvido, que é predominantemente ocidental e do norte. Nem toda a humanidade está no mesmo barco. No entanto, eu diria que a ideia da humanidade como um todo contém uma importante força normativa que chama a nossa atenção para problemas que não podem ser resolvidos em escala nacional ou regional. Nesse sentido, a noção de humanidade afirma a importância humana do agenciamento, em contraste com uma invocação despolitizada da humanidade como sem sujeito.

\section{O Antropoceno e o tempo histórico}

As implicações totais do Antropoceno para as ciências sociais provavelmente recairão nas interfaces das temporalidades geológica (Terra), biológica (vida) e histórica (sociedades humanas). Estas constituem diferentes modalidades de evolução e atuam umas sobre as outras de maneiras diferentes. A natureza dessas interações e a evolução resultante não foram adequadamente estudadas. 
Há relatos - como o trabalho de Fernand Braudel (1990) - sobre influências ambientais na formação histórica de longo prazo das sociedades. Mais recentemente, Jared Diamond (1998, 2005), em dois estudos inovadores sobre as influências da vida biológica nas sociedades humanas, mostrou o que acontece com as sociedades que não se localizam em seu ambiente natural. Em uma obra inspirada no Antropoceno, Costanza, Graumlich e Steffen,(2011) tentaram produzir uma história integrada da vida humana em relação à história natural. Os autores argumentaram que as sociedades respondem aos sinais climáticos de várias maneiras, partindo de colapso ou falha, migração e mitigação criativa. Em sua opinião, a resposta futura e os feedbacks do sistema humano-ambiental dependerão da compreensão do passado global. Eles argumentam:

Examinar sistemas socioecológicos através de múltiplas escalas de tempo possibilita identificar os antecedentes bastante remotos de fenômenos importantes que ocorrem em uma era ou época específica (Costanza et alii, 2011: 13).

Agora é cada vez mais reconhecido que a evolução humana e biológica e a história da Terra estão entrelaçadas. No entanto, acho que o argumento pode ir além de demonstrar os limites ambientais das sociedades humanas. Alguns destes foram identificados por Clark e Gunaratnam (2017), que destacam, acompanhando Brooke (2014) e Davis (2001), que convulsões sociais significativas coincidiram com grandes mudanças geofísicas. Em uma época como a nossa, na qual a mudança climática tem um impacto crescente na política global, é provável que vejamos mais convulsão social. No momento, é provável que se deem na direção do avançado hemisfério ocidental e norte, mas é possível prever que, num futuro não muito distante, a migração seja para fora da Europa, devido às mudanças climáticas resultantes do derretimento da calota de gelo do Ártico.

As sociedades humanas e os seres humanos não são apenas condicionados pelo ambiente natural, mas devem ser vistos em termos históricos profundos como incorporados na história natural da Terra. A noção de "história profunda" foi apresentada para apresentar uma nova leitura da história, na qual a história recente - a modernidade - é moldada em um intervalo de tempo bem mais longo, o que nos permite ver mais claramente que o tempo histórico está incrustado na história natural da Terra. O quadro temporal da história baseia-se na divisão da história e da pré-história, segundo o qual a história começa com o advento da escrita. Esforços recentes dos historiadores para superar essa divisão da pré-história e da história procuram trazer o Neolítico e o Paleolítico para a discussão, como parte de uma "história profunda" da vida humana (Shryock \& Smail, 2011; Smail, 2008). Esse aprofundamento do arcabouço histórico possibilita que a história seja espacial- 
mente ampliada para abranger áreas e domínios de experiência não previamente incluídos no tempo histórico que dá predominância às civilizações eurasianas da "Era Axial" (Mota, 2016). Por este prisma, o presente pode ser visto sob uma luz diferente e não dominado exclusivamente por entidades espacialmente delimitadas, a exemplo das nações. A história profunda desafia a teoria da história do século XIX, associada a Rank, Langlois e Seignobos, a afirmar que o passado não escrito é incognoscível. Ao contrário do que agora pode ser considerada uma breve história da humanidade, produzida pela civilização cristã europeia, a história profunda considera uma história comum que remonta à África Oriental, onde o Homo sapiens surgiu. Não pode haver dúvida de que uma história profunda da humanidade, que supera a divisão da pré-história e da história, oferece base para pensar a subjetividade humana de maneira a desafiar as concepções eurocêntricas de história e subjetividade. E também nos força a repensar a centralidade da modernidade e, possivelmente, o avanço evolucionário que veio com a evolução dos humanos modernos - há 50 mil anos, mostrando, por exemplo, semelhanças com hominídeos anteriores.

No entanto, o verdadeiro desafio ainda não foi abordado: como conectar as diferentes lógicas da evolução que se manifestam na história natural do planeta, a transformação da vida e da consciência humanas dos primeiros hominídeos até o Homo sapiens sapiens, a ascensão e transformação das sociedades humanas. 0 entrelaçamento de biologia, evolução do cérebro, modelagem do comportamento humano, e formação das sociedades humanas estão profundamente conectados por coevolução. No entanto, as lógicas - os mecanismos e processos - desses domínios evolutivos são muito diferentes. Se a ideia de Antropoceno é que ele tenha um sentido importante para além de mais um termo nas Escalas de Tempo Geológico, ele deve abranger essas esferas evolucionárias. Já é evidente que o Antropoceno não seja mais apenas um conceito ou uma teoria, mas um modelo cultural através do qual as sociedades contemporâneas podem ver a si mesmas em termos de uma escala maior de significado (Strydom, 2017). Por estas razões, depois de tudo, não estou convencido de que a ideia de modernidade não seja mais relevante. Somente a modernidade pode livrar as sociedades modernas da condição perigosa que elas criaram.

Nesse sentido, então, o Antropoceno está relacionado a outras ideias da modernidade que possuem um significado normativo, como responsabilidade, verdade e justiça. A atração da história profunda pela correção dos relatos convencionais da história que se concentra apenas no mundo moderno não aborda adequadamente o fato de que as soluções para os problemas do mundo moderno não serão encontradas no início da história da humanidade. 
Há aqueles que argumentam com considerável convicção de que o Antropoceno e o capitalismo são coesos e, portanto, deveríamos falar de um "Capitaloceno" em vez de um Antropoceno. Os efeitos sistêmicos da atividade humana sobre a Terra certamente devem ser atribuídos ao capitalismo, e não à humanidade, no sentido abstrato do termo. Como modelo cultural, a ideia do Antropoceno é mais do que a condição do capitalismo, mas inclui também a consciência da condição histórica da vida humana. É por isso que acredito que a noção do Antropoceno é compatível com a visão de que é o capitalismo a força geradora da destruição planetária. Mas ela também contém uma dimensão política.

A ideia do Antropoceno - argumento eu - sugere um novo modo de pensar a constituição do político. Nesse sentido, é uma forma mais elaborada de pensar a noção de sociedade de risco que Ulrich Beck (2006) viu como base de uma concepção cosmopolítica do político. O Antropoceno não é simplesmente uma condição objetiva da mudança planetária, ou outro termo para a mudança climática, mas é também uma categoria interpretativa pela qual as sociedades contemporâneas refletem sobre si mesmas e sobre a própria vida e reinventam seu espaço e tempo. 0 Antropoceno não é, assim, um conceito politicamente neutro, mas contém fortes elementos normativos, incluindo significações imaginárias. As dimensões normativas não são claras, como as explicações científicas, porque o curso da ação política é controverso. É controverso de várias maneiras, em termos de quem seja o sujeito político, da natureza dos problemas objetivos e as possíveis soluções.

A política do Antropoceno pode ser vista em termos interpretativos como modos de conhecer e conter um componente imaginário, no sentido de imaginar possibilidades futuras e redefinir o presente para realizar tais possibilidades. Isto pareceria aproximar-se da ideia de cosmopolitismo, que se preocupa também, principalmente, com uma visão do mundo sob um escopo político. A noção de Antropoceno pode ser dada em termos de cosmopolitismo, mas também pode oferecer um pensamento cosmopolita com um novo destaque que permita desafiar mais firmemente o neoliberalismo e sua resposta mais positiva à globalização. Alguns dos objetivos centrais do Antropoceno, como condição política, ressoam com ideias cosmopolíticas, por exemplo, o aumento da diversidade biológica, a necessidade de um diálogo global entre o mundo desenvolvido e o mundo em desenvolvimento, a redução das emissões de carbono de maneira que se respeite o desejo do mundo não ocidental de uma participação nos benefícios que até agora foram confinados ao mundo ocidental, a necessidade de encontrar um equilíbrio entre o pensamento de curto e longo prazo. 


\section{Conclusão}

Concluirei com um número de observações e proposições sobre as implicações da ideia do Antropoceno para a sociologia e para a ciência social em geral.

A Terra não é uma realidade objetiva estável na qual as sociedades humanas são construídas, mas está emaranhada no mundo humano e social de formas que desafiam as suposições ontológicas de grande parte do pensamento social moderno.

Desenvolvimentos na ciência do Sistema Terra, em particular na geologia, abriram novas perspectivas que desafiam a visão pós-positivista da ciência e a ideia de que as ciências naturais e sociais estão baseadas em epistemologias muito diferentes.

As implicações para a ontologia social demonstram que, com a formação de um novo estrato de rocha, os humanos são os criadores da superfície rochosa da Terra. O inumano (rocha) recebeu um novo significado e importância.

Como observado por outros, especialmente por Latour, precisamos ir além do dualismo natureza versus sociedade, que está subjacente em muito do pensamento social moderno. No entanto, isso não justifica necessariamente uma posição pós-humanista. Certamente questiona a tradição fenomenológica e interpretativa da ciência social de um mundo social que existe independentemente do mundo natural.

Embora a geologia tenha adquirido recentemente um novo significado para a ciência social, não creio que deva haver uma "geologização" da ciência social. No entanto, as ciências sociais devem ser capazes de se envolver de forma mais produtiva com as ciências naturais, em particular com a ciência do Sistema Terra e as ciências da vida.

O Antropoceno é um modo de saber o mundo. Como tal, é mais que um conceito; é também um modelo epistêmico e um modelo cultural.

É uma forma de abordar grandes transformações históricas que abrangem a mudança social, natural e humana. 


\section{Referências}

BECK, U. The cosmopolitan outlook. Cambridge: Polity Press, 2006.

BRAUDEL, F. The Mediterranean and the Mediterranean World in the Age of Philip XI. London: Penguin, 1990 [1987].

BROOKE, J. Climate change and the course of global history. Cambridge: Cambridge University Press, 2014.

CHAKRABARTY, D. The climate of history: four theses. Critical Inquiry, v. 35, p. 197222, 2009.

CHERNILO, D. Debating humanity: towards a philosophical sociology. Cambridge (UK): Cambridge University Press, 2017.

CLARK, N.; GUNARATNAM, Y. Earthing the anthropos? From "socialising the Anthropocene to geologizing the social". European Journal of Social Theory, v. 20, n. 1, p. 146-163, 2017.

COSTANZA, R.; GRAUMLICH, L.; STEFFEN, W. (Eds.). Sustainability or collapse? An integrated history and future of people on Earth. Cambridge (MA): MIT Press, 2011 [2007].

DAVIS, M. Late Victorian Holocausts: El nino famines and the making of the Third World. London: Verso, 2001.

DIAMOND, J. Collapse: how societies chose to fall or survive. London: Penguin, 2011 [2005].

. Guns, germs and steel: a short history of everybody for the last 13,000 years. New York: Vintage, 1998.

LOVEJOY, A. Gaia: A new look at life on Earth. Oxford: Oxford University Press, 2000 [1979].

LUKE, T. Reconstructing social theory and the Anthropocene. European Journal of Social Theory, v. 20, n.1, p. 80-94, 2017.

MCNEILL, J. R.; ENGELKE, P. The great acceleration: an environmental history of the Anthropocene. Cambridge (MA): Harvard University Press, 2014.

MILLS, C. W. The sociological imagination. London: Penguin, 1970 [1959].

MITHEN, S. The prehistory of the mind. London: Phoenix, 1998. 
MOTA, A. Uncivilized civilizations. Social Imaginaries, v. 2, n. 4, 2016.

STEFFEN, W. et alii. The Anthropocene: from global change to planetary stewardship. Ambio, v. 40, p. 739-761, 2011.

PINKER, S. The better angels of our nature: a history of violence and humanity. London: Penguin, 2011.

RUSSELL, E. Evolutionary history: uniting history and biology to understand life on Earth. Cambridge (MA): Cambridge University Press, 2011.

SHRYOCK, A.; SMAIL, D. L. (Eds.). Deep history: the architecture of past and present. Berkeley (CA): University of California Press, 2011.

SMAIL, D. L. On deep history and the brain. Berkley (CA): University of California Press, 2008.

STEFFEN, W.; GRINEVALD, J.; CRUTZEN, P.; MCNEIL, J. The Anthropocene: conceptual and historical perspectives. Philosophical Transactions of the Royal Society, v. 369, p. 842-67, 2011.

STEFFEN, W. et alii. The trajectory of the Anthropocene: the great acceleration. The Anthropocene Review, v. 2, n. 1, p. 81-98, 2015.

STRYDOM, P. The sociocultural self-creation of a natural category: social-theoretical reflections on human agency under the temporal conditions of the Anthropocene. European Journal of Social Theory, v. 20, n. 1, p. 61-79, 2017.

THOMAS, J. A. History and biology in the Anthropocene: problems of scale, problems of value. American Historical Review, v. 119, n. 5, p. 1587-1607, 2014.

TURNER, B. S. Ritual, belief and habituation: religion and religions form the axial age to the Anthropocene. European Journal of Social Theory, v. 20, n. 1, p. 132-145, 2017.

ZALASIEWICZ, J.; WILLIAMS, M.; HAYWOOD, A.; ELLIS, M. The Anthropocene: a new epoch of geological time? Philosophical Transactions of the Royal Society, $v$. 369, p. 835-841, 2011. 